\title{
Rita Franceschini
}

\section{»In einer anderen Sprache« oder: wie hebt man feine Unterschiede?}

\author{
Einleitung
}

Das Themenheft hätte auch den Titel tragen können »fast >Muttersprache««, um auszudrücken, dass es um jene sprachlichen Kompetenzen, Prozesse und Produkte geht, die in ihrem Erscheinen einen leichten, verfremdenden Eindruck hinterlassen. Demnach geht es um die Frage, woran es liegt, dass einige Produktionen feine Irritationen verursachen, leicht ungewöhnliche Formen und Ausdrücke zeigen und Rede- und Schreibweisen aufweisen, die an eine >andere Sprache< denken lassen.

Die Beiträge loten feine, kleine Unterschiede aus und heben sie in ihrer subtilen Differenz hervor. Im Fokus steht das >fast Gleiche und doch wieder Andere $<$. Um diesen Lupeneffekt auf Mikrophänomene deutlich zu machen, ist es wesentlich, die methodischen Vorgehensweisen und das Instrumentarium darzulegen: Weil unser Thema keine traditionell verankerte und theoretisch eindeutig umrissene Fragestellung behandelt, sondern eher ein Feld ausmisst, ist es umso notwendiger, das Nachvollziehen der Beobachtung der Unterschiede für den Leser/die Leserin sicherzustellen.

Es handelt sich um ein denkbar breites Themenspektrum. In diesem Heft befassen sich Beiträge bspw. mit jenen Kompetenzen, die beim Spracherwerb fast jenen gleichkommen, die man >native speakern< zuweist. Nicht nur diese advanced learners stehen im Mittelpunkt - junge wie erwachsene -, sondern auch Schreibende, die sich in einer anderen Sprache ausdrücken und Texte, die Spuren der anderen Sprache durchscheinen lassen. Fragen der kulturellen Filter und der Transkulturalität kommen wiederholt zur Sprache. Privilegierte Untersuchungsgegenstände sind in der Folge demnach fortgeschrittene und sich entwickelnde Lernersprachen, Übersetzungsphänomene und die literarische Sprachwahl.

Der Beitrag von Christiane v. Stutterheim und Mary Carroll geht der Frage nach, wie weit fortgeschrittene Lerner einer Zweitsprache Erzählaufgaben bewältigen. Die Besonderheiten lassen einen »kognitiven Akzent« ausmachen, die diese Sprecher im Vergleich zu nativen kennzeichnen. Nachgewiesen werden diese Eigenheiten anhand der sprachlichen Mittel zur Sachverhaltsdarstellung. Die Beispiele betreffen das Sprachenpaar Deutsch-Englisch.

Demselben Sprachenpaar gehen Rosemary Tracy und Ira GawlitzekMaiwald nach. Ihr Beitrag ist der Entwicklung und Ausdifferenzierung der 
zwei Erstsprachen eines Kindes, das frühkindlich bilingual aufwächst, gewidmet. Anhand von Fallstudien werden sowohl synchrone wie asynchrone Entwicklungen aufgezeigt, im Verlauf deren die starke und schwache Sprache mehrmals wechseln können. Syntaktische Phänomene stehen im Vordergrund und das Konzept des bootstrapping.

Diesen Beiträgen, die sich mit Prozessen und Produkten von zweisprachigen Individuen befassen, folgt der Beitrag von Erich Steiner, welcher das Augenmerk auf textliche Spuren lenkt. Seine Überlegungen gründen auf umfangreichen Analysen des Übersetzungsprozesses zwischen deutschen und englischen Texten. Prominent wird der Frage des Durchscheinens der einen in der anderen Sprache (dem sog. shining through) sowie anderen subtilen Phänomenen, die in einem umfangreichen Forschungsprojekt untersucht werden sollen, nachgegangen. Beim Vergleich von Texten aus demselben Register wird deutlich, dass übersetzte Texte normalisierter sind und neutralisierte Formen bevorzugen.

Ebenfalls Übersetzungsphänomenen ist der nachfolgende Beitrag von Juliane House gewidmet. Speziell an populärwissenschaftlichen Texten wird den > versteckten Unterschieden $<$ um dem $>$ kulturellen Filter $<$ v.a. der subjektivischen oder passivischen Ausdrucksweisen nachgegangen, die in den letzten dreißig Jahren einen shift erfahren haben. Wieder steht das Sprachenpaar Deutsch-Englisch im Vordergrund, doch wird auch die Frage aufgeworfen, wie es zu einer geringeren Ausprägung dieser Phänomene in romanischen Sprachen (Französisch und Spanisch) kommt.

Anhand eines breit verstandenen Begriffs von italienischem Sprachraum als literarisches Feld wird abschließend von Immacolata Amodeo das Konzept der polyzentrischen Literatur anhand eines summarischen historischen Abrisses bis hin zu aktueller Poesie illustriert: Italienisch als >fast-Muttersprache < der überwiegend dialektalen Sprecher der Halbinsel über die Jahrhunderte ist hierbei ein extensives, sprechendes Beispiel zum vorliegenden Themenheft. Zur regionalen Diversifikation kommen heute Literaturproduktionen von italienischen Emigranten im Ausland und nun auch von Italienisch schreibenden Immigranten in Italien hinzu, die ihr mehrsprachiges Repertoire zum literarischen Ausdruck nutzen.

Die liminaren Unterschiede im Sprach- und Kulturkontakt zu heben birgt sicherlich noch weiteres Potential für Literaturwissenschaft und Linguistik in sich. Eine scharf oppositive, kontrastive Herangehensweise würde dabei dem Phänomenbereich nicht gerecht werden. Unterschiedliche Methodologien und Theoriebezüge nutzend - wie im vorliegenden Band -, scheint den Blick eher freizulegen hin zu einer subtilen, kultursensitiven Auslotung der Differenzproblematik. 